\title{
Procurement of Global Logistics Services Using Combinatorial Auctions
}

\author{
Nikesh Kumar Srivastava, N. Viswanadham, and S. Kameshwaran
}

\begin{abstract}
Global logistics flows have increased dramatically in recent years due to the globalization in the world economy. It is more complex than the domestic logistics, consisting of multiple services like multi-modal transportation, cross-docking, storage, and customs clearance. Two issues are in order with multitude of services spanning across international borders: First, a single logistics provider may not be able to provide all the services and second, performance non-conformance with any of the services will affect the entire flow. We address the above issues in this paper by proposing a procurement that allows combinatorial bidding with quality of service measures as business constraints.
\end{abstract}

\section{INTRODUCTION}

Logistics is concerned with the broad range of activities concerned with effective and efficient movement of semifinished or finished goods from one business to another and from manufacturers/distributors/retailers to the end consumers. This include freight transportation, warehousing, material handling, protective packaging, cross docking, order processing, and documentations. It amounts to $10-15 \%$ of every product produced and is estimated to be at USD 3.5 Trillion worldwide almost equally divided between North America, Europe and Asia. The competitiveness of the economies thus can be enhanced by adopting promising new technologies and next generation logistics thinking.

Traditionally manufacturers handled all logistics functions including trucking and warehousing through own logistics departments. Trucking and warehousing were then procured from first party logistics (1PL) providers, who were individual owners of trucks and warehouses. Large scale transportation lead to procuring service from second party logistics (2PL) providers like a transportation company that owns a fleet of vehicles. In the recent past, logistics services were outsourced to third party logistics (3PL) providers. 3PLs are non-asset based providers, who manage the endto-end process by procuring the transportation and other services from 2PLs and 1PLs. Currently, there is 4PL, who is an integrator that assembles the resources, capabilities, and technology of its own organization and other organizations to design, build and run comprehensive supply chain solutions.

The above emergence of logistics providers with varying functionalities and capabilities have led to various logistics

Nikesh Kumar Srivastava is a researcher at the Centre for Global Logistics and Manufacturing Strategies, Indian School of Business, Hyderabad, 500032, India Nikesh_Srivastava@isb.edu

N. Viswanadham is the Executive Director of the Centre for Global Logistics and Manufacturing Strategies, Indian School of Business, Hyderabad, 500032, India N_ Viswanadhame isb.edu

$\mathrm{S}$. Kameshwaran is a researcher at the Centre for Global Logistics and Manufacturing Strategies, Indian School of Business, Hyderabad 500032, India Kameshwaran_Seisb.edu procurement scenarios. In [1], procurement of two kinds of logistics services were identified: basic and advanced. Basic services are the single services like transport from A to $\mathrm{B}$ with tangible service definitions. The transaction is one-time for the current demand, with no contractual agreements for future requirements. Currently, such services can be purchased on the Internet from freight exchanges. On the other hand, advanced services comprises of multiple and bundled services with intangible outcome requirements. This refers to purchasing of 3PL services with contractual agreements to transport goods in future for a specified period of time. In this paper, our focus is on procuring a on-demand global logistics service, which is composed of many basic services.

Foreign trade by its very nature involves multi-modal transportation and customs clearances across international borders. Further, there may be cross docking at transhipment hubs. A global logistics service is thus composed of many logistics services like multi-modal freight transfer, packaging, cross-docking, warehousing and other supporting services like customs clearance, trade documentation, exception notification, exception handling, etc. A 3PL which manages such a global flow will procure the above component services from 2PLs, 1PLs, and other 3PLs. In this paper, we propose a procurement methodology based on combinatorial auctions for buying the component services. The logistics providers can bid for a bundle of services using combinatorial bids. Further, we incorporate different quality of service measures in evaluating the bids, in addition to the traditional factors of cost and lead time. This allows the buying 3PL to ensure its own service levels that has been committed to the shipper.

The paper is organized as follows. Section II describes global logistics flow and the need for combinatorial bids in its procurement. In section III, QoS measurements relevant to logistics services are discussed. The proposed procurement methodology with combinatorial bids is described in section IV. A 0-1 integer programming model is presented to solve the resulting bid evaluation problem. Section V illustrates the applicability of the proposed methodology using a numerical example and section VI concludes the paper.

\section{Global Logistics}

Globalization and the increasing outsourcing of manufacturing and sourcing operations to the low cost countries have resulted in advanced and complex logistics services. Consider a hi-tech electronic manufacturer in Hong Kong, who wants to ship its products to Bangalore in India. As shown in figure 1, the preferred route is via Singapore (transhipment hub) and Chennai (port of entry). The cargo 


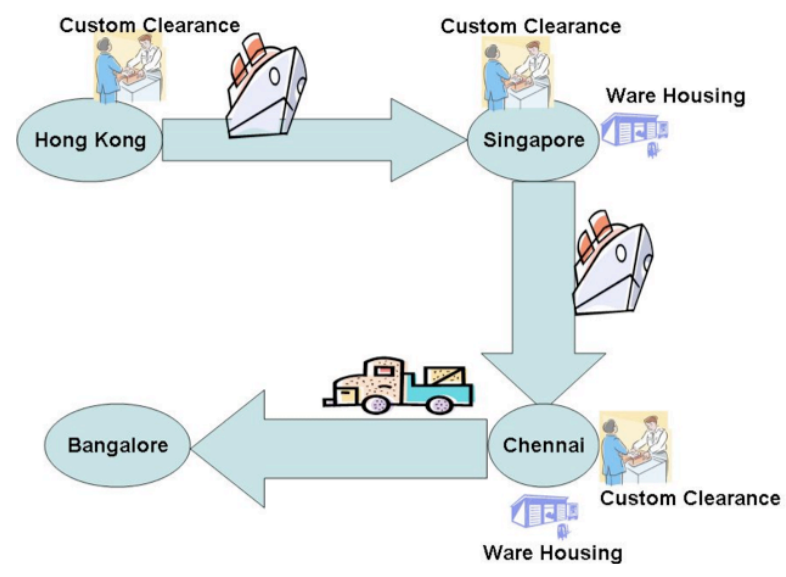

Fig. 1. Global Logistics Scenario

is transported by ships till Chennai and then by trucks to Bangalore. It is composed of several services like trade documentation, customs clearance at various points, crossdocking, and multi-modal transportation. Some services like the customs clearance and cross-docking at Singapore can naturally be bundled and provided by a single 2PL or 3PL. On the other hand, shipping from Singapore to Chennai and from Chennai to Bangalore, can possibly be provided by a single provider or by two different providers.

To allow for the possibility of providing bundled services, we propose the use of combinatorial bids. A procurement process, with suppliers bidding and the buyer evaluating the bids, borders on the auction mechanism. Combinatorial auctions (CA) [5], are useful for procuring a set of heterogeneous, but related items. CA allows package bidding, that is, quoting a single cost for a bundle (subset) of items. CA has been used in industrial procurement of multiple items [11].

Several applications have been identified for combinatorial auctions in freight transportation [3]. Use of combinatorial auctions for transportation services by various companies like Home Depot, Wal-Mart, and Staples are described in [6]. An early application of combinatorial auctions at Reynolds Metal Company is given in [13]. Porter et al. [15] describe a 1992 application of combinatorial auctions by Sears Logistics Services. In [16], the benefit of using combinatorial auctions for the procurement of transportation services for the lanes is described. In particular they have shown, that combinatorial auctions results in lower cost to shippers, while maintaining high service levels. Ledyard. et al. [9], explores how combined value auctions can be used for procurement of transportation services. We show in this paper the application of combinatorial auctions in the global logistics procurement scenario.

\section{Logistics Performance Measures}

Global logistics is a composite service consisting of multiple services, possibly provided by different service providers. Non-conformance of any one service in terms of delayed delivery or mishandling leading to damages will affect the subsequent services and in effect the total service. Though not widely prevalent, logistics organizations are working towards using a set of holistic performance measures. Such performance measures can quantify the quality of service at various levels and will be useful in differentiating the service providers. In this paper, we propose the use of performance measures in selecting the service providers. In [7], several logistics performance measures were defined with respect to various services like warehousing, packaging, transportation, and documentation. For example, an end-to-end logistics order can be measured with respect to the following attributes [7].

- Perfect entry (the entry is exactly what the customer wants) by the means (telephone or direct entry) the customer desire in a single entry

- Perfect fillable with exact quantity of each item available for delivery within the customer-specified delivery window

- Perfect picking with correct quantities of the correct items

- Perfect packaging with customer-designated packaging and labeling

- Perfect shipping without damage

- Perfect delivery in customer-designated time window and to customer- designated location

- Perfect communication with order status report available 24 hours a day

- Perfect billing with on-time payment

- Perfect documentation with customer-specified documentation means, including paper, fax,EDI, and/or Internet

Let $P_{j}$ denote the performance with respect to attribute $j$ in $[0,1]$. Then the total perfect order performance (POP) (assuming performance-independence) is given by

$$
P O P=\prod_{j} P_{j}
$$

Suppose each of the above nine activities were performed correctly $90 \%$ percent of the time. Then more than $60 \%$ of order would we imperfect. We extend this principle in selecting service providers for global logistics service. Let $q_{j}(S)$ denote the performance measure of service $S$ for the attribute $j$. As a global logistics service is composed of many services, the composite performance measure is given by

$$
Q_{j}=\prod_{S} q_{j}(S)
$$

Further, the services can be provided by different providers. If $Q_{j}$ is the target level of performance for attribute $j$, say 0.95 , then the service providers have to be selected for each service $S$ such that the product of their individual $q_{j}(S)$ is greater than or equal to the target $Q_{j}$. The individual performance values $q_{j}(S)$ can be determined from the past transactions with the service provider. For example, if the attribute is on-time arrival, then it can be measured as the ratio of number of on-time arrivals to the total number of transactions. We assume that this knowledge is available to a 3PL who is choosing the service providers. As 3PLs 
are non-asset based service providers, they ascertain various performance measures while choosing 2PLs or 1PLs in order to maintain their own service measure to the shippers. In the next section, we use this knowledge of 3PLs in choosing the service providers.

\section{Global Logistics Procurement}

Based on the above discussions, one can infer the following regarding the procurement of global logistics services.

- Global logistics services is composed of multiple services related to various activities of flow of physical goods and information.

- The entire service needs to be fulfilled by different service providers.

- A service provider can provide more than one service by bundling.

- Performance measures need to be taken into account in selecting the service providers.

In this section, we propose a procurement framework thats takes into account the above. In particular, we use the expressive combinatorial bids to allow the service providers to bid for bundle of services. In bid evaluation, performance measures are used as side constraints to select the appropriate service providers.

\section{A. Design Issues}

The procurement process with RFP and bidding is inherently based on auctions and hence the design principles generally follow auction design. Auctions can categorized based on the dynamics as: (1) one-shot or single-round auctions and (2) progressive or iterative or multiple-round auctions. One-shot auctions are sealed bid auctions, which has a single bidding phase, during which all the bidders submit their bids. Progressive auctions can be sealed bid or open bid, but has multiple rounds of bidding phases. At the end of each bidding phase, there will be flow of information from the auctioneer to the bidders. This will help the bidders to prepare their bids for the next bidding phase. The design parameters of one-shot auctions are bidding language, bid evaluation policy, and pricing policy. The bidding language specifies the format of bids, the bid evaluation policy describes the technique to determine the winners, and the pricing policy determines the price of the winning goods. On the other hand, design of progressive auctions is relatively non-trivial, which includes the specification of bidding language, bid evaluation technique at each bidding round, information exchange at the end of each round, termination condition, and the pricing policy. However, the progressive auction has many advantages over its one-shot counterpart [4], especially in procurement [14]. We design here only the one-shot procurement that is commonly used in logistics procurement.

The procurement process with the RFP and the bidding, only borders on auctions and are indeed less formally structured than auctions. The auction design is generally based on the principles of mechanism design. Mechanism design [10] is the sub-field of microeconomics and game theory that considers how to implement good system-wide solutions to problems that involve multiple self-interested agents, each with private information about their preferences. The mechanism design methodology has also been found useful in designing e-markets [17]. One of the main assumptions in mechanism design is that the rules of the auction is a common knowledge to all the participating agents. In procurement, though the rules of bid submission are common knowledge, rules of bid evaluation may not be revealed to the service providers. For example, the $3 \mathrm{PL}$ that is procuring a the logistics service may not reveal to the bidders (2PLs and 1PLs) the target performance levels $Q_{j}$, which will be used in evaluating the bids. We consider only the design issues related to bid structure and bid evaluation. We use the first price or pay-as-bid pricing policy (the suppliers are paid the cost quoted in the bid), which is the commonly used pricing policy in practice.

Based on the one-shot dynamics, procurement considered in this paper consists of the following phases: (1) RFP generation and distribution by the buyer, (2) sealed bid submission by the suppliers during a predefined bidding interval, and (3) bid evaluation by the buyer (after the expiration of the bidding interval) to determine the winning bids.

\section{B. RFP and Bid Submission}

The RFP specifies the required global logistics service and its component services. In the example of shipping from Hong Kong to Bangalore, the RFP will also mention the component services like trade documentation, shipping from Hong Kong to Singapore, from Singapore to Chennai, etc and their time frames. Further, RFP will also specify the allowable bundles of the above services. Let $A$ denote the set of all services with index $k$ to denote a single service. A allowable bundle of services that can be offered by a single logistics provider is given by $S \subseteq A$. Note that $S$ can be a singleton set consisting of a single service, but for brevity we refer $S$ as simply a bundle. The index $i$ denote a service provider from the set $N$. For each $i$, let $B_{i}$ denote the set of bundles for which bids have been submitted from $i$. The cost quoted in the bid by $i$ for providing the bundle $S$ is $C_{i}(S)$. Note that the performance measures are not included in the bid definition or submission. It is used only in the bid evaluation by the 3PL seeking the service using its internal estimation of the measures based on past transactions.

\section{Bid Evaluation}

The bid evaluation problem faced by the 3PL is to select the logistics providers for each of the component services such the target performance measures are met and total cost of procurement is minimized. We model this as a 0-1 integer programming problem. Let $y_{i}(S)$ denote a binary decision variable to select or reject the service provider $i$ for providing $S$. The performance measure of $i$ for the service $S$ with respect to the attribute $j$ is $q_{j}^{i}(S)$. If the target measure for the attribute is $Q_{j}$, then the constraint can be linearized as 


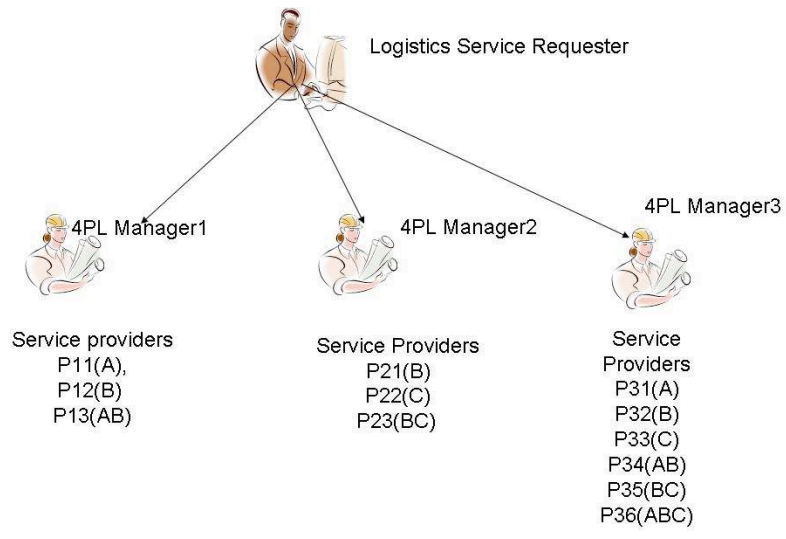

Fig. 2. Logistics Service Procurement Scenario

follows:

$$
\ln \left(Q_{j}\right) \leq \sum_{S \in B_{i}} \sum_{i \in N} \ln \left(q_{j}^{i}(S)\right) y_{i}(S)
$$

The $y_{i}(S)=1$ indicates that $i$ has been selected to provide the service $S$ and $y_{i}(S)=0$ indicates otherwise. The above is calculated over all the services (bundle or component). It is possible that the attribute $j$ may not be relevant to some services. For example, attribute that measures the damages in packaging and handling is not relevant to the services like customs clearance or trade documentation. In such cases, we assume the $q_{j}^{i}(S)=1$. The complete $0-1$ integer programming formulation is as follows.

$$
\min \sum_{S \in B_{i}} \sum_{i \in N} C_{i}(S) y_{i}(S)
$$

subject to

$$
\begin{array}{cl}
\sum_{S: k \in S} \sum_{i: S \in B_{i}} y_{i}(S)=1 & \forall k \in A \\
\ln \left(Q_{j}\right) \leq \sum_{S \in B_{i}} \sum_{i \in N} \ln \left(q_{j}^{i}(S)\right) y_{i}(S) & \forall j \\
y_{i}(S) \in\{0,1\} \quad \forall S \in B_{i}, \forall i \in N &
\end{array}
$$

The constraints (5) ensure that each service is provided by only one provider and (6) are the performance constraints.

\section{NUMERICAL EXPERIMENT}

To show the efficacy of proposed methodology we conduct experiment with three 4PL logistics providers and 3 logistics services $\{A, B, C\}$. Bid submitted by them can be seen in Table I, this bid is generated based on information submitted by the alternative service provider (2PLs and 3PLs) associated toS each $4 \mathrm{PL}$ logistics providers . QoS associated with service can be seen in Table II. We solve the problem for specified target level of performance set by the logistics service requester (LSR), see Table III. Result of numerical experiment is in table IV. Data has been generated manually keeping real logistics service procurement situation in mind. This optimization problem has been solved using ILOGCPLEX which is commercial software for solving integer programming.

\section{CONCLUSION}

In the global supply chain arena choice of logistics provider is an important decision. In the management literature there are papers describing 3PL and 4PL and their operations and their value delivery to the entire supply chain. There are also contributions in the transportation part of the logistics on how to choose the lanes of operation for achieving both scale and scope economies. Logistics industry has created companies that can provide multi-modal services and can operate globally. They provide single window services for end to end logistics operations. In this paper, we developed mathematical model to select logistics service providers for a global logistics service.

The proposed methodology can be extended in many ways to meet the practical requirements. Currently the bid structure only allows price quotation and time frames are given by the buyer. This restricts the scope of carriers who can bid. Alternatively, inclusion of time frame (within certain limits) in the bids will lead to a more profitable procurement. The bidding dynamics adopted in this paper is one-shot, but progressive multi-round auctions have many advantages, especially for combinatorial bids. There are many design methodologies for progressive auctions [2], [8], [12], [14] for procurement. It will be interesting to investigate the design of progressive auctions for the proposed procurement with time factor in the bids.

\section{REFERENCES}

[1] D. Andersson and A. Norrman, "Procurement of logistics services - a minutes work or a multi-year project?" European Journal of Purchasing and Supply Management, vol. 8, pp. 3-14, 2002.

[2] S. Bikhchandani and J. Ostroy, "Ascending price Vickrey auctions," Forthcoming in Games and Economic Behavior, 2005.

[3] C. Caplice and Y. Sheffi, "Combinatorial auctions for truckload transportation," in Combinatorial Auctions, P. Cramton, Y. Shoham, and R. Steinberg, Eds. MIT Press, 2006, ch. 21.

[4] P. Cramton, "Ascending auctions," European Economic Review, vol. 42, pp. 745-756, 1998.

[5] P. Cramton, Y. Shoham, and R. Steinberg, Combinatorial Auctions. Cambridge: MIT Press, 2005.

[6] W. Elmaghraby and P. Keskinocak, "Combinatorial auctions in procurement," in Practice of Supply Chain Management: Where Theory and Practice Converge. Kluwer Academic Publishers, 2003.

[7] E. Frazelle, Supply Chain Strategy. New York: McGraw-Hill, 2001.

[8] S. Kameshwaran, L. Benyoucef, and X. Xie, "Design of progressive auctions for procurement based on Lagrangian relaxation," in Proceedings of IEEE International Conference on E-Commerce Technology (CEC 2005). IEEE Computer Society, 2005, pp. 9-16.

[9] J. Ledyard, M. Olson, D. Porter, J. Swanson, and D. Torma, "The first use of a combined value auction for transportation services," Interfaces, vol. 32, no. 5, pp. 4-12, 2002.

[10] A. Mas-Colell, M. D. Whinston, and J. R. Green, Microeconomic Theory. New York: Oxford University Press, 1995.

[11] D. Mishra, "Auction design for multi-item procurement," PhD Thesis, University of Wisconsin-Madison, Wisconsin, 2004.

[12] D. Mishra and D. C. Parkes, "Ascending price Vickrey auctions using primal-dual algorithms," Harvard Univeristy, Tech. Rep., 2004.

[13] E. W. Moore, J. M. Warmke, and L. R. Gorban, "The indispensable role of management science in centralizing freight operations at Reynolds Metals Company," Interfaces, vol. 21, pp. 107-129, 1991.

[14] D. C. Parkes and J. Kalagnanam, "Models for iterative multiattribute procurement auctions," Management Science, vol. 51, pp. 435-451, 2005, special Issue on Electronic Markets.

[15] D. Porter, D. P. Torma, J. O. Ledyard, J. A. Swanson, and M. Olson, "The first use of a combined-value auction for transportation services," Interfaces, vol. 32, no. 5, pp. 4-12, 2002. 


\begin{tabular}{|c|c|c|c|}
\hline No & LSP & $\begin{array}{c}\text { Composite } \\
\text { Service }(\mathrm{S})\end{array}$ & $\begin{array}{c}\text { Cost/Unit } \\
(\$) C_{i}(S)\end{array}$ \\
\hline 1 & $P_{11}$ & $\mathrm{~A}$ & 150 \\
2 & $P_{12}$ & $\mathrm{~B}$ & 100 \\
3 & $P_{13}$ & $\mathrm{AB}$ & 200 \\
\hline 4 & $P_{21}$ & $\mathrm{~B}$ & 120 \\
5 & $P_{22}$ & $\mathrm{C}$ & 190 \\
6 & $P_{23}$ & $\mathrm{BC}$ & 300 \\
\hline 7 & $P_{31}$ & $\mathrm{~A}$ & 130 \\
8 & $P_{32}$ & $\mathrm{~B}$ & 110 \\
9 & $P_{33}$ & $\mathrm{C}$ & 190 \\
10 & $P_{34}$ & $\mathrm{AB}$ & 230 \\
11 & $P_{35}$ & $\mathrm{BC}$ & 290 \\
12 & $P_{36}$ & $\mathrm{ABC}$ & 400 \\
\hline
\end{tabular}

TABLE I

Bid SubmitTed By EACH SERVICE PROVIDER

\begin{tabular}{|c|c|c|c|c|c|c|c|c|c|c|}
\hline No & Service(S) & $\begin{array}{l}\text { Perfect } \\
\text { Entry }\end{array}$ & $\begin{array}{l}\text { Perfect } \\
\text { Fillable }\end{array}$ & $\begin{array}{l}\text { Perfect } \\
\text { Picking }\end{array}$ & $\begin{array}{c}\text { Perfect } \\
\text { Packaging }\end{array}$ & $\begin{array}{c}\text { Perfect } \\
\text { Shipping }\end{array}$ & $\begin{array}{c}\text { Perfect } \\
\text { Delivery }\end{array}$ & $\begin{array}{c}\text { Perfect } \\
\text { Communication }\end{array}$ & $\begin{array}{l}\text { Perfect } \\
\text { Billing }\end{array}$ & $\begin{array}{c}\text { Perfect } \\
\text { Documentation }\end{array}$ \\
\hline 1 & A & 0.95 & 0.98 & 0.96 & 0.99 & 0.99 & 0.99 & 0.99 & 0.99 & 0.99 \\
\hline 2 & $\mathrm{~B}$ & 0.95 & 0.98 & 0.96 & 0.99 & 0.99 & 0.99 & 0.99 & 0.99 & 0.99 \\
\hline 3 & $\mathrm{AB}$ & 0.9025 & 0.9604 & 0.9216 & 0.9801 & 0.9801 & 0.9801 & 0.9801 & 0.9801 & 0.9801 \\
\hline 4 & B & 0.95 & 0.98 & 0.96 & 0.99 & 0.99 & 0.99 & 0.99 & 0.99 & 0.99 \\
\hline 5 & $\mathrm{C}$ & 0.95 & 0.98 & 0.96 & 0.99 & 0.99 & 0.99 & 0.99 & 0.99 & 0.99 \\
\hline 6 & $\mathrm{BC}$ & 0.9025 & 0.9604 & 0.9216 & 0.9801 & 0.9801 & 0.9801 & 0.9801 & 0.9801 & 0.9801 \\
\hline 7 & $\mathrm{~A}$ & 0.95 & 0.98 & 0.96 & 0.99 & 0.99 & 0.99 & 0.99 & 0.99 & 0.99 \\
\hline 8 & B & 0.95 & 0.98 & 0.96 & 0.99 & 0.99 & 0.99 & 0.99 & 0.99 & 0.99 \\
\hline 9 & $\mathrm{C}$ & 0.95 & 0.98 & 0.96 & 0.99 & 0.99 & 0.99 & 0.99 & 0.99 & 0.99 \\
\hline 10 & AB & 0.9025 & 0.9604 & 0.9216 & 0.9801 & 0.9801 & 0.9801 & 0.9801 & 0.9801 & 0.9801 \\
\hline 11 & $\mathrm{BC}$ & 0.9025 & 0.9604 & 0.9216 & 0.9801 & 0.9801 & 0.9801 & 0.9801 & 0.9801 & 0.9801 \\
\hline 12 & $\mathrm{ABC}$ & 0.8573 & 0.9411 & 0.97 & 0.97 & 0.97 & 0.97 & 0.97 & 0.97 & 0.97 \\
\hline
\end{tabular}

TABLE II

QOS ATTRIBUTE FOR EACH LOGISTICS SERVICE

\begin{tabular}{|c|c|}
\hline $\begin{array}{c}\text { Performance } \\
\text { Attribute }(j)\end{array}$ & $\begin{array}{c}\text { Target Performance } \\
\text { Level }\end{array}$ \\
\hline Perfect Entry & 0.8 \\
\hline Perfect Fillable & 0.9 \\
\hline Perfect Picking & 0.9 \\
\hline Perfect Packaging & 0.9 \\
\hline Perfect Shipping & 0.9 \\
\hline Perfect Delivery & 0.9 \\
\hline Perfect Communication & 0.9 \\
\hline Perfect Billing & 0.9 \\
\hline Documentation & 0.9 \\
\hline
\end{tabular}

TABLE III

QOS DESIRED By LOGISTICS SERVICE REQUESTER (LSR)

\begin{tabular}{|c|c|c|c|}
\hline Selected Provider & Selected Service & Total Cost & Overall POP \\
\hline$\left\{P_{13}, P_{33}\right\}$ & $\{(\mathrm{AB}),(\mathrm{C})\}$ & $390 \$$ & $65.33 \%$ \\
\hline
\end{tabular}

TABLE IV

RESULT 
[16] J. Song and A. Regan, "Combinatorial auctions for transportation service procurment:the carrier perspective," University of California, Irvine, Tech. Rep., 2002.

[17] H. Varian, "Economic mechanism design for computerized agents," University of California, Berkeley, Tech. Rep., 2000. 